\title{
Lymphovascular Invasion as a Prognostic Factor in Non-Metastatic Adenocarcinoma of Esophagogastric Junction After Radical Surgery
}

This article was published in the following Dove Press journal: Cancer Management and Research

\author{
Chengbin Zheng $\mathbb{D}^{1, *}$ \\ Xingyu Feng ${ }^{2} * *$ \\ Jiabin Zheng ${ }^{2}$ \\ Qian Yan ${ }^{2}$ \\ $\mathrm{Xu} \mathrm{Hu}{ }^{2}$ \\ Huolun Feng ${ }^{2}$ \\ Zhenru Deng ${ }^{2}$ \\ Qianchao Liao ${ }^{2}$ \\ Junjiang Wang $\mathbb{D}^{2}$ \\ Yong $\mathrm{Li}^{1,2}$
}

'Department of General Surgery,

Guangdong Provincial People's Hospital;

Guangdong Academy of Medical Sciences,

School of Medicine, South China

University of Technology, Guangzhou,

Guangdong 510080, People's Republic of

China; ${ }^{2}$ Department of General Surgery,

Guangdong Provincial People's Hospital;

Guangdong Academy of Medical Sciences,

Guangzhou, Guangdong 510080, People's

Republic of China

*These authors contributed equally to this work
Correspondence: Yong $\mathrm{Li}$

Department of General Surgery,

Guangdong Provincial People's Hospital,

Guangdong Academy of Medical Sciences,

School of Medicine, South China

University of Technology, 106 Zhongshan

Road 2, Guangzhou, Guangzhou 510080,

People's Republic of China

Tel +86- | 3822177479

$\mathrm{Fax}+86-020-83827812$

Email liyong@gdph.org.cn
Purpose: Tumors with lymphovascular invasion (LVI) are thought to be associated with lymph node metastasis and to lead to a worse prognosis. However, the effect of LVI on the prognosis of adenocarcinoma of esophagogastric junction (AEG) is still unclear.

Patients and Methods: We retrospectively analyzed 224 consecutive patients with nonmetastatic AEG who underwent radical surgery in our hospital from 2004 to 2018. Inverse probability weighting (IPW) analysis was used to eliminate the selection bias. IPW-adjusted Kaplan-Meier curves and Cox proportional hazards models were used to compare diseasespecific survival (DSS) and overall survival (OS) between patients with and without LVI.

Results: A total of 224 patients with non-metastatic AEG who underwent radical resection were included in the study and 96 (42.9\%) patients developed LVI. Survival analysis showed that LVI were associated with worse DSS (hazard ratio (HR) $=3.12$; 95\% CI: $1.93-5.03$ ) and worse OS (HR $=2.33$; 95\% CI: 1.61-3.38). The results were consistent across subgroups stratified by pathologic N stage. Subgroup analysis demonstrated that Siewert type III (HR= 3.20, 95\% CI: 1.45-7.06) was associated with worse DSS, but not Siewert type I/II (HR= 1.46, 95\% CI: 0.94-2.31, P-interaction=0.047).

Conclusion: LVI are associated with worse prognosis in AEG. LVI had a worse effect on DSS in Siewert type III AEG than Siewert type I/II AEG.

Keywords: lymphovascular invasion, adenocarcinoma of esophagogastric junction, risk factor, overall survival, disease-specific survival

\section{Introduction}

Adenocarcinoma of esophagogastric junction (AEG) is a tumor located in the area $5 \mathrm{~cm}$ above and below the esophagogastric junction (EGJ) and crossing or involving the EGJ. ${ }^{1}$ In the past few decades, the incidence of AEG has been on the rise in both western and eastern countries, ${ }^{2-4}$ and the proportion of AEG in esophageal and gastric cancer is also on the rise. ${ }^{3}$ EGJ is the junction of the tubular esophagus and the stomach. When tumors invade or cross the EGJ, the clinicopathological features of the tumors may not only integrate the characteristics of esophageal and gastric cancer but also be different from them. For example, previous studies have found that the Lauren type, lymph node metastasis and tumor differentiation are prognostic risk factors for esophageal cancer and gastric cancer, and these prognostic factors have also been confirmed in AEG. ${ }^{5,6}$ However, the TMN staging of AJCC/UICC 8th edition unified the staging of esophageal cancer and gastric cancer according to the distance between the tumor center and EGJ. AEG can be 
considered a subtype of adenocarcinoma of the lower esophagus or the stomach, but there is still something special about it.

The incidence of lymphovascular invasion (LVI) of AEG appears to be higher than that of esophageal and gastric cancers. ${ }^{7}$ The incidence of LVI is $15.7 \%-50.4 \%$ in esophageal cancer, ${ }^{8-10} 12.9 \%-27.8 \%$ in gastric cancer $^{11-13}$ and as high as $49.9 \%$ to $77.6 \%$ in AEG. ${ }^{6,7,14}$ LVI is considered to be a risk factor for metastasis and recurrence in esophageal and gastric cancer. ${ }^{8,11,15-17}$ Most studies have focused on the impact of LVI on lymph node metastasis rather than as an independent risk factor for prognosis. It has been reported in a previous study that LVI were an independent risk factor for prognosis of some tumors. ${ }^{11,18,19}$ However, whether the influence of LVI on AEG in long-term survival is still not be well answered and remained controversial. ${ }^{14,20,21}$

There are few reports on whether LVI affect long-term survival in AEG. Therefore, the objective of our study was to investigate occurrence of LVI and their impact on overall survival and disease-specific survival in AEG.

\section{Patients and Methods}

\section{Patients}

We retrospectively collected the clinicopathological data of patients with non-metastatic AEG who received radical surgical resection in Guangdong Provincial People's Hospital from January 2004 to November 2018. Inclusion criteria: (1) tumor that had invaded or crossed the EGJ; (2) pathological diagnosis of adenocarcinoma; (3) no distant metastasis; (4) radical surgery; (5) complete clinicopathological data available; (6) follow-up data available. Exclusion criteria: (1) tumor did not invade or cross the EGJ; (2) pathologic diagnosis was squamous cell carcinoma or adeno-squamous carcinoma; (3) Siewert type could not be determined; (4) patient was unwilling or unable to participate in follow-up. All clinicopathological data were extracted from the hospital inpatient management system.

\section{Pathologic Evaluation}

The clinicopathological data included age, sex, Siewert type, LVI, tumor size, degree of tumor differentiation, pathological $\mathrm{T}$ stage, pathological $\mathrm{N}$ stage, immunohistochemical Her2 expression and Ki67 status. Hematoxylin \& eosin (HE) staining was performed to evaluate the presence of venous invasion, and IHC stain for D2-40 was performed using a mouse monoclonal antibody against human lymphatic endothelium antigen to evaluate lymphatic invasion. Tissue slides of each patient were reviewed by pathologists to ensure a LVI present or absent. The tumors were classified by the Siewert classification, ${ }^{22}$ which was divided into types I, II and III based on the patient's gastroscopy, computed tomography, digestive tract radiography and postoperative pathological data. Pathological $\mathrm{T}$ staging and $\mathrm{N}$ staging were based on the TNM staging standards of the AJCC and UICC 8th edition. Siewert type I and Siewert type II refer to stages of esophageal cancer, ${ }^{23}$ and Siewert type III refers to stages of gastric cancer. ${ }^{24}$ Her2 was defined as positive when the immunohistochemistry outcome was $3+$ and above. The lymph node ratio was defined as the number of positive lymph node metastases divided by the total number of lymph nodes removed during the operation.

\section{Follow-Up}

We conducted regular postoperative follow-up using outpatient services, telephone calls and communication software every 3 months for the first 2 years, every 6 months for the 3 rd to 5 th years, and every 1 year after the 5 th year. Disease-specific survival (DSS) associated with the cancer and overall survival (OS) were defined, respectively, as the period from the date of surgical treatment to the date of tumor death and death from any cause or the last date of follow-up. We reconfirmed the survival status of all patients in November 2019.

\section{Statistical Analyses}

Continuous variables are expressed as the mean $\pm \mathrm{SD}$, and categorical variables were reported as frequencies with percentages. Student's $t$ test or the Mann-Whitney test was used for intergroup comparisons of continuous variables, whereas the $\chi^{2}$ test or Fisher's test was used to compare categorical data. Variables with statistically significant differences in chi-square analysis $(\mathrm{P}<0.1)$ were included in the multivariate logistic regression analysis. The statistical analysis was performed using SPSS software, version 25.0 (SPSS, Chicago, IL, USA).

In order to eliminate the selection bias and the effect of $\mathrm{pN}$ stage, which was highly correlated with LVI in the effect on DSS and OS, we adjusted the characteristics of the group with and without LVI by using the inverse probability weighting (IPW) method. Adjustment variables included age, sex, tumor size, Siewert type, degree of differentiation, $\mathrm{pT}$ stage, $\mathrm{pN}$ stage, lymph node ratio, 
Her2 expression, Ki67\%, preoperative and postoperative chemotherapy and surgical approach, all of which might have been correlated with tumor prognosis. The median follow-up time was calculated by the reverse KaplanMeier method. IPW-adjusted Kaplan-Meier curves and the Cox proportional hazard model were used to compare DSS and OS between two groups. The Cox proportional hazard model was used to compare DSS and OS with or without LVI in subgroup analyses of sex, Siewert type, tumor differentiation, $\mathrm{pT}$ stage and $\mathrm{pN}$ stage. We also conducted an interaction test to assess the heterogeneity of effects across the subgroups. The above statistical analysis was done by using $\mathrm{R}$, version 3.5.1 ( $\mathrm{R}$ Core Team 2019, Vienna, Austria). The IPW adjustment was conducted using the "survival" packages. All $\mathrm{P}$ values are 2 -sided. A $\mathrm{P}$ value of $<0.05$ was considered statistically significant.

\section{Results}

\section{Study Population Features}

A total of 224 patients with non-metastatic AEG who underwent radical resection were included in the study. The clinicopathological features are shown in Table 1. The study population included 166 males and 58 females. The average age of the patients was 62.8 years, ranging from 30 to 86 years. A total of $136(60.7 \%)$ were Siewert type I and type II, and 88 (39.3\%) were Siewert type III. All Siewert type I AEG patients underwent a transthoracic surgery. 71\% of type II AEG patients received a transthoracic surgery and $29 \%$ of type II AEG patients underwent transhiatal surgery. Twenty-three $(10.3 \%)$ patients received preoperative chemotherapy, and 89 (39.7\%) patients received postoperative adjuvant chemotherapy.

\section{Baseline Characteristics in Unadjusted and IPW Adjusted Data}

There were 96 (42.9\%) patients with LVI and 128 (57.1\%) patients without LVI. Age, tumor size, Siewert classification, degree of differentiation, $\mathrm{pT}$ stage, $\mathrm{pN}$ stage, Her2 expression, and lymph node ratio were different between the two groups, as shown in Table $1(\mathrm{P}<0.1)$. The LVI group exhibited younger age, larger tumors, a higher proportion of Siewert type III tumors, lower differentiation degree, higher pT and pN stages, lower Her2 expression, and higher lymph node ratio. After IPW adjustment for age, sex, tumor size, Siewert type, degree of differentiation, $\mathrm{pT}$ stage, $\mathrm{pN}$ stage, lymph node ratio, Her2 expression, Ki67\%, preoperative and postoperative chemotherapy and surgical approach, the standardized difference (SD) for all characteristics was $<0.1$, indicating that the weighted population in the 2 groups was subsequently comparable, as shown in Table 1. Binary multivariate logistic regression analysis showed that Siewert type III, $\mathrm{pN}$ stage, and lymph node metastasis were risk factors for the occurrence of LVI. The odds ratios (ORs) (95\% confidence intervals $(95 \%$ CIs)) were 2.08 (1.02-$4.25), 2.25$ (1.05-4.82) and 1.04 (1.02-1.06), respectively, as shown in Table 2.

\section{DSS for AEG Patients with or Without LVI}

The median follow-up time of DSS was 48 months, with a $95 \%$ CI of 39.3-56.7 months. The median DSS survival age in the unweighted study population was 87 months, with a 95\% CI of 71.8-102.2 months. The 1-year, 3-year, and 5-year DSS of patients with LVI was $83.7 \%, 57.3 \%$ and $40.3 \%$, respectively, and $96.8 \%, 86.6 \%$ and $70.2 \%$ in patients without LVI, respectively. The difference in survival between the two groups in the unweighted study population was statistically significant $(\mathrm{P}<0.001$, Figure 1A). There was still a significant difference in survival between the two groups in the weighted study population $(\mathrm{P}=0.025$, Figure $1 \mathrm{~B})$. In the regression analysis of Cox proportional risk adjusted by IPW, LVI were associated with poor DSS (HR $=3.12$; 95\% CI: 1.93-5.03).

\section{OS for AEG Patients with or Without LVI}

The median follow-up time of OS was 64 months, with a 95\% CI of 59.4-69.6 months. The median OS in the unweighted study population was 54 months, with a $95 \%$ CI of 44.8-63.2 months. The 1-year, 3-year, and 5-year OS of patients with LVI was $79.6 \%, 46.9 \%$ and $27.9 \%$, respectively, and $92.9 \%, 76.3 \%$ and $48.2 \%$ in patients without LVI, respectively. The difference in survival between the two groups in the unweighted study population was statistically significant $(\mathrm{P}<0.001$, Figure 1C). There was still a significant difference in survival between the two groups in the weighted study population ( $\mathrm{P}=0.037$, Figure $1 \mathrm{D})$. In the regression analysis of Cox proportional risk adjusted by IPW, LVI were associated with poor $\mathrm{OS}(\mathrm{HR}=2.33 ; 95 \% \mathrm{CI}: 1.61-3.38)$.

\section{Subgroup Analysis}

We conducted a subgroup analysis of sex, Siewert type, tumor differentiation, $\mathrm{pT}$ stage and $\mathrm{pN}$ stage (Figures 2 and 3). LVI were associated with a significantly poorer 
Table I Baseline Characteristics of AEG Patients with or without LVI in Unweighted and Weighted Study Population

\begin{tabular}{|c|c|c|c|c|c|c|c|c|}
\hline & \multirow[t]{2}{*}{$\begin{array}{l}\text { Number of Patients }(\%) \\
(\mathrm{N}=224)\end{array}$} & \multicolumn{3}{|c|}{$\begin{array}{l}\text { Unweighted Study Population, } \\
\text { NO.\% }\end{array}$} & \multirow[b]{2}{*}{ SD } & \multicolumn{3}{|c|}{ Weighted Study Population,\% } \\
\hline & & $\begin{array}{l}\text { LVI(+) } \\
(n=96)\end{array}$ & $\begin{array}{l}\text { LVI(-) } \\
(n=128)\end{array}$ & $\mathbf{P}$ & & $\begin{array}{l}\text { LVI(+) } \\
(n=96)\end{array}$ & $\begin{array}{l}\text { LVI(-) } \\
(n=128)\end{array}$ & SD \\
\hline Age(years), SD & $62.8 \pm 9.6$ & $61.1 \pm 9.4$ & $64.0 \pm 9.5$ & $0.022 *$ & 0.311 & $62.6 \pm 9.9$ & $62.6 \pm 10.1$ & 0.005 \\
\hline \multicolumn{9}{|l|}{ Sex } \\
\hline $\begin{array}{l}\text { Male } \\
\text { Female } \\
\text { Tumor size } \\
\text { (cm), SD }\end{array}$ & $\begin{array}{l}166(74.10) \\
58(25.90) \\
5.0 \pm 2.2\end{array}$ & $\begin{array}{l}72(75.0) \\
24(25.0) \\
5.4 \pm 2.0\end{array}$ & $\begin{array}{l}94(73.4) \\
34(26.6) \\
4.8 \pm 2.3\end{array}$ & $\begin{array}{l}0.792 \\
0.043 *\end{array}$ & $\begin{array}{l}0.036 \\
0.277\end{array}$ & $\begin{array}{l}71.1 \\
29.9 \\
4.9 \pm 1.9\end{array}$ & $\begin{array}{l}73.2 \\
26.8 \\
5.1 \pm 2.5\end{array}$ & $\begin{array}{l}0.068 \\
0.091\end{array}$ \\
\hline \multicolumn{9}{|l|}{ Siewert type } \\
\hline $\begin{array}{l}\text { I+II } \\
\text { III }\end{array}$ & $\begin{array}{l}136(60.7 \mid) \\
88(39.29)\end{array}$ & $\begin{array}{l}49(51.0) \\
47(49.0)\end{array}$ & $\begin{array}{l}87(68.0) \\
41(32.0)\end{array}$ & $0.010 *$ & 0.312 & $\begin{array}{l}66.0 \\
34.0\end{array}$ & $\begin{array}{l}66.7 \\
33.3\end{array}$ & 0.016 \\
\hline \multicolumn{9}{|l|}{ Differentiation } \\
\hline $\begin{array}{l}\text { Moderate-high } \\
\text { Low }\end{array}$ & $\begin{array}{l}110(49.11) \\
114(50.89)\end{array}$ & $\begin{array}{l}36(37.5) \\
60(62.5)\end{array}$ & $\begin{array}{l}74(57.8) \\
54(42.2)\end{array}$ & $0.008 *$ & 0.415 & $\begin{array}{l}49.5 \\
50.5\end{array}$ & $\begin{array}{l}51.3 \\
48.7\end{array}$ & 0.037 \\
\hline \multicolumn{9}{|l|}{ pT stage } \\
\hline $\begin{array}{l}\mathrm{TI}-2 \\
\mathrm{~T} 3-4\end{array}$ & $\begin{array}{l}41(18.30) \\
183(81.70)\end{array}$ & $\begin{array}{l}9(9.4) \\
87(90.6)\end{array}$ & $\begin{array}{l}32(25.0) \\
96(75.0)\end{array}$ & $0.003 *$ & 0.407 & $\begin{array}{l}15.9 \\
84.1\end{array}$ & $\begin{array}{l}18.9 \\
81.1\end{array}$ & 0.078 \\
\hline \multicolumn{9}{|l|}{ pN stage } \\
\hline $\begin{array}{l}\text { pN0-I } \\
\text { pN2-3 }\end{array}$ & $\begin{array}{l}124(55.36) \\
100(44.63)\end{array}$ & $\begin{array}{l}29(30.2) \\
67(69.8)\end{array}$ & $\begin{array}{l}95(74.2) \\
33(25.8)\end{array}$ & $<0.00 I^{*}$ & 0.981 & $\begin{array}{l}61.5 \\
38.5\end{array}$ & $\begin{array}{l}58.6 \\
42.4\end{array}$ & 0.078 \\
\hline \multicolumn{9}{|l|}{ Her2 } \\
\hline $\begin{array}{l}\text { Negative } \\
\text { Positive } \\
\text { Ki67 (\%), SD } \\
\text { LN ratio (\%), SD }\end{array}$ & $\begin{array}{l}\text { II } 3(50.45) \\
\text { III ( }(49.55) \\
59.6 \pm 22.7 \\
24.3 \pm 26.5\end{array}$ & $\begin{array}{l}73(76.0) \\
23(24.0) \\
59.5 \pm 22.5 \\
39.4 \pm 27.9\end{array}$ & $\begin{array}{l}82(64.1) \\
46(35.9) \\
58.7 \pm 23.0 \\
13.0 \pm 18.6\end{array}$ & $\begin{array}{l}0.055 \\
0.967 \\
<0.001 *\end{array}$ & $\begin{array}{l}0.204 \\
0.007 \\
1.114\end{array}$ & $\begin{array}{l}66.8 \\
33.2 \\
58.8 \pm 22.3 \\
24.2 \pm 25.9\end{array}$ & $\begin{array}{l}68.9 \\
31.1 \\
60.0 \pm 23.1 \\
22.6 \pm 26.0\end{array}$ & $\begin{array}{l}0.043 \\
0.052 \\
0.064\end{array}$ \\
\hline \multicolumn{9}{|l|}{ Surgical approach } \\
\hline $\begin{array}{l}\text { Transabdominal } \\
\text { Transthoracic } \\
\text { Other }\end{array}$ & $\begin{array}{l}160(71.4) \\
57(25.4) \\
7(3.1)\end{array}$ & $\begin{array}{l}73(76.0) \\
22(22.9) \\
I(1.1)\end{array}$ & $\begin{array}{l}87(68.0) \\
35(27.3) \\
6(4.7)\end{array}$ & 0.149 & 0.254 & $\begin{array}{l}72.5 \\
23.4 \\
4.2\end{array}$ & $\begin{array}{l}70.3 \\
26.4 \\
3.3\end{array}$ & 0.081 \\
\hline \multicolumn{9}{|l|}{ Neoadjuvant } \\
\hline $\begin{array}{l}\text { Yes } \\
\text { No }\end{array}$ & $\begin{array}{l}23(10.26) \\
201(89.74)\end{array}$ & $\begin{array}{l}\text { II (II.5) } \\
85(88.5)\end{array}$ & $\begin{array}{l}12(9.4) \\
116(90.6)\end{array}$ & 0.611 & 0.068 & $\begin{array}{l}9.5 \\
90.5\end{array}$ & $\begin{array}{l}10.0 \\
90.0\end{array}$ & 0.016 \\
\hline \multicolumn{9}{|l|}{ Adjuvant } \\
\hline $\begin{array}{l}\text { Yes } \\
\text { No }\end{array}$ & $\begin{array}{l}89(39.73) \\
135(61.27)\end{array}$ & $\begin{array}{l}40(4 I .7) \\
56(59.3)\end{array}$ & $\begin{array}{l}49(38.3) \\
79(61.7)\end{array}$ & 0.608 & 0.069 & $\begin{array}{l}38.5 \\
61.5\end{array}$ & $\begin{array}{l}39.3 \\
60.7\end{array}$ & 0.017 \\
\hline
\end{tabular}

Notes: SD Standardized Difference; $* P<0.05$. 
Table 2 Multivariable Logistic Regression Model Predicting with or Without LVI in the Unweighted Study Population

\begin{tabular}{|c|c|c|c|}
\hline & OR & $95 \% \mathrm{Cl}$ & $P$ \\
\hline Age & 0.98 & $0.95-1.02$ & 0.318 \\
\hline \multicolumn{4}{|l|}{ Siewert type } \\
\hline$|+| \mid$ & 1 & I & \\
\hline III & 2.08 & $1.02-4.25$ & $0.045^{*}$ \\
\hline Tumor size $(\mathrm{cm})$ & 1.13 & $0.96-1.36$ & 0.134 \\
\hline \multicolumn{4}{|l|}{ pT stage } \\
\hline PTI-2 & I & 1 & \\
\hline pT3-4 & 1.50 & $0.56-4.01$ & 0.421 \\
\hline \multicolumn{4}{|l|}{ pN stage } \\
\hline pN0-I & 1 & 1 & \\
\hline pN2-3 & 2.25 & I.05-4.82 & $0.038 *$ \\
\hline \multicolumn{4}{|l|}{ Differentiation } \\
\hline Moderate-high & 1 & I & \\
\hline Low & 1.31 & $0.67-2.56$ & 0.431 \\
\hline \multicolumn{4}{|l|}{ Her2 } \\
\hline Negative & 1 & 1 & \\
\hline Positive & 1.04 & $0.54-2.08$ & 0.877 \\
\hline LN ratio (\%) & 1.04 & $1.02-1.06$ & $<0.001 *$ \\
\hline Neoadjuvant & 1.09 & $0.37-3.24$ & 0.878 \\
\hline
\end{tabular}

Note: $* P<0.05$.

DSS across differentiation and $\mathrm{pN}$ stage subgroups and a significantly poorer OS across sex, Siewert type, differentiation, $\mathrm{pT}$ and $\mathrm{pN}$ stage subgroup (P-interaction $>0.05$ ). Subgroup analysis according to Siewert type demonstrated that Siewert type III $(\mathrm{HR}=3.20,95 \% \mathrm{CI}: 1.45-7.06)$ was associated with worse DSS, but not Siewert type I/II (HR= 1.46, 95\% CI: 0.94-2.31, P-interaction=0.047).

\section{Discussion}

In recent years, due to the increasing incidence of AEG, it has attracted much attention and has been classified by the UICC as a distinct tumor category from esophageal cancer and gastric cancer. A deeper understanding of AEG will benefit to precision therapy.

In this single-institution series of 224 AEGs, $42.9 \%$ of AEG patients had LVI. Siewert Type I/II AEG is often considered to be distal adenocarcinoma of esophageal cancer, while Siewert Type III is considered to be similar to gastric cancer, but its incidence of LVI seems higher than that of esophageal cancer and gastric cancer. ${ }^{8,11}$ LVI is thought to precede or occur coincidently with lymph node metastasis. This is reflected by the correlation between LVI and $\mathrm{pN}$ and $\mathrm{pT}$ stage, lymph node ratios in our study. Our analysis clearly shows that LVI is associated with more tumor pathology, as tumor location and tumor size. Multivariate analysis confirmed that Siewert classification and lymph node metastasis were confirmed highly related to LVI.

Siewert type III AEG is more prone to developing LVI. We found that the incidence of LVI in Siewert type III tumors (53.4\%) was higher than in Siewert type I/II $(36 \%)$, which is consistent with previous data. ${ }^{7}$ The risk of developing LVI in Siewert type III AEG was 2.08 times higher than in Siewert type I/II (OR 2.08, 95\% CI: $1.02-$ 4.25). One potential explanation for the discrepancies between AEG I/II and AEG III is that the pathogenesis of these tumor entities is markedly different. Siewert type III tumors are thought to be associated with chronic atrophic gastritis ${ }^{25}$ and involve no reflux. Therefore, mucosal atrophy is more likely to occur in Siewert type III. $^{7}$ Chronic atrophic inflammation causes the gastric folds to become thin and flat, the mucus decreases, the mucosa becomes thinner, and sometimes the mucosal vessels can be seen through. On this mucosal background, tumor cells are more likely to invade the lymphovascular vessel and develop LVI. Comparatively, Siewert type I/II tumors are thought to be associated with gastroesophageal reflux disease and Barrett's esophagus, ${ }^{26}$ which might result in stepwise degradation of lymphatic vessels. ${ }^{14}$ In addition, its pathological changes are mainly metaplasia and hyperplasia. Tumor cells seem to have more difficulty penetrating the proliferating epithelium into the lymphovascular vessel.

LVI is also generally considered impact on lymph node metastasis in esophageal cancer, ${ }^{8,27}$ gastric cancer $^{11}$ and AEG. ${ }^{28}$ In this study, the risk of LVI was increasing with the pN stage (OR: 2.25, 95\% CI: 1.05-4.82) and lymph node ratios (OR: 1.04, 95\% CI: 1.02-1.06). In the process of tumor development, the tumor intrudes into the lymphovascular vessel, and the tumor cells invade the lymphovascular vessel to metastasize to regional lymph nodes or distant sites. At this tumor stage, to some degree, the presence of LVI indicates the risk of metastasis, while lymph node metastasis also indicates the possible existence of LVI. In the early stage of cancer, if the lymph node metastasis is negative in clinical diagnosis, the absence of LVI is an important condition for the decision on endoscopic resection. ${ }^{11,29}$ 
A

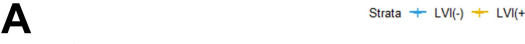

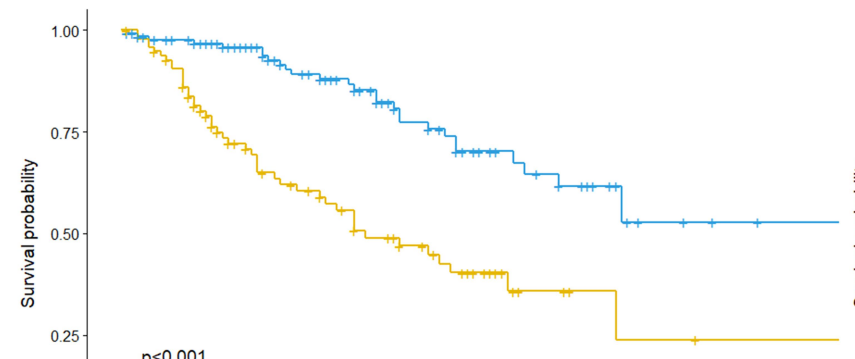

Unadjusted K-M curves for DSS
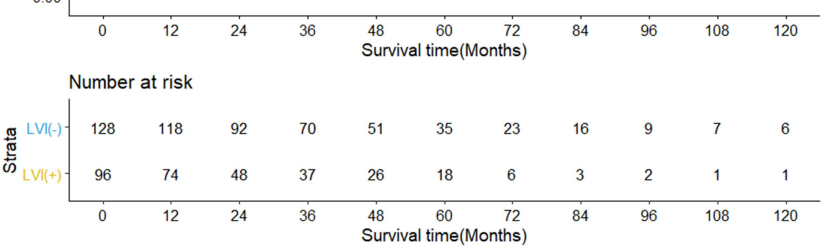

C

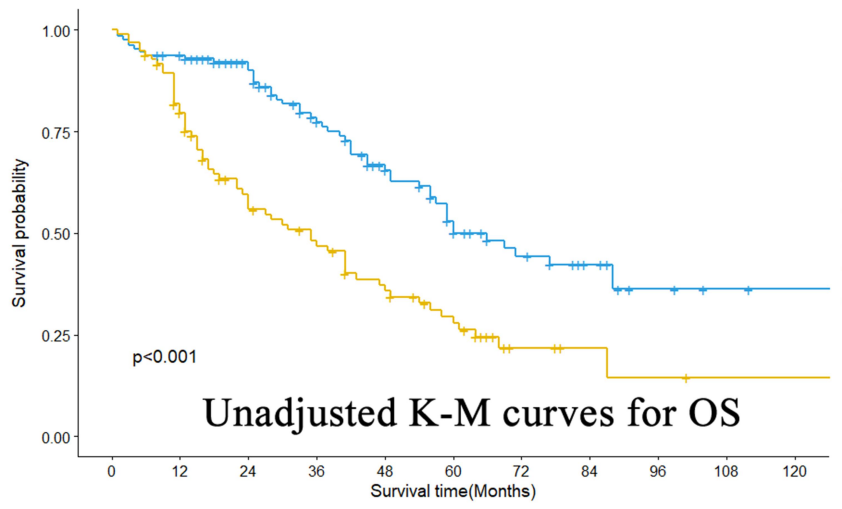

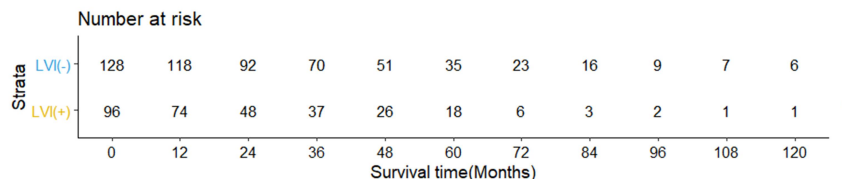

B

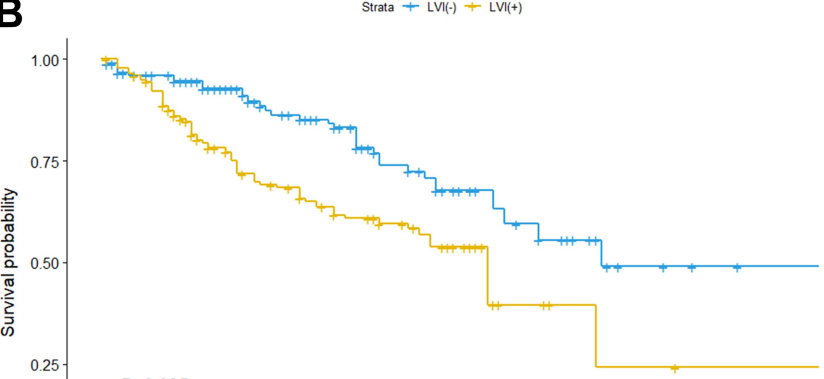

$\mathrm{P}=0.025$

IPW-adjusted K-M curves for DSS

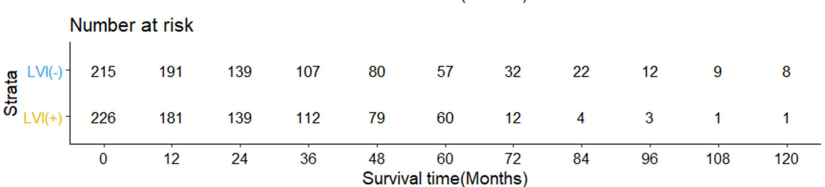

D Strata + LVI(-) + LVI(+)

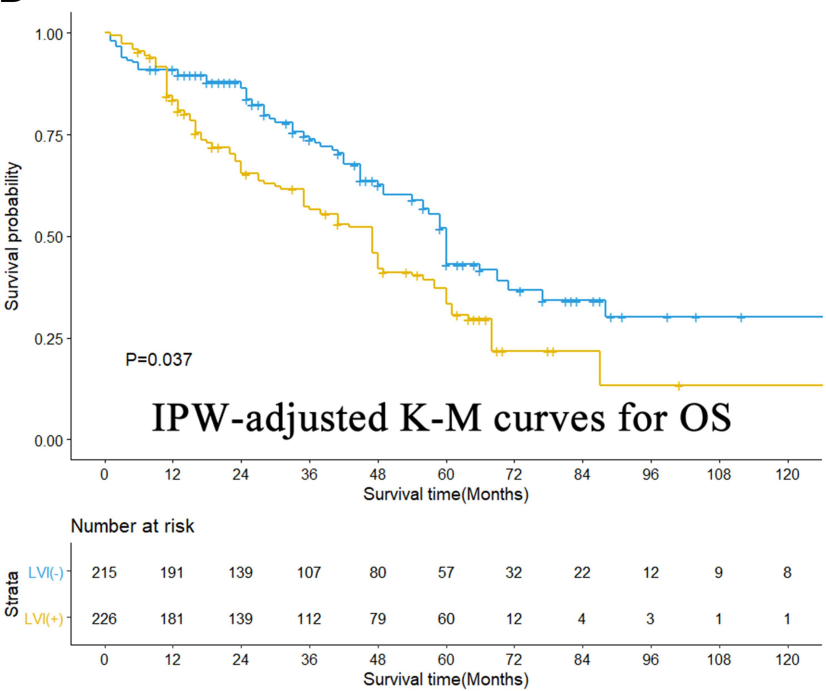

Figure I Unadjusted and IPW-adjusted Kaplan-Meier analysis of disease-specific survival (DSS) and overall survival (OS) in patients with non-metastatic adenocarcinoma of esophagogastric junction after radical surgery. (A) Unadjusted K-M curves for DSS. (B) IPW-adjusted K-M curves for DSS. (C) Unadjusted K-M curves for OS. (D) IPWadjusted K-M curves for OS.

According to previous studies, LVI is an independent risk factor for prognosis of esophageal and gastric cancer. ${ }^{11,19,30}$ Similar to esophageal and gastric cancer, is LVI an independent risk factor for long-term survival of AEG? Burkhard et $\mathrm{al}^{14}$ demonstrate the prognostic significance of LVI in patients with AEG tumors, with marked differences between the subgroups AEG I versus AEG II/ III. But in another study, LVI were not predictive for overall survival. ${ }^{21}$ Besides, Sjoerd et $\mathrm{al}^{20}$ considered LVI as a "considerable" prognosis risk factor but not a "strong" factor. Our results support LVI as an independent prognostic factor in AEG. We used IPW analysis not normally Cox multivariate regression analysis to avoid the interaction of lymph node metastasis. IPW-adjusted survival analysis showed that LVI were associated with worse DSS (hazard ratio (HR) $=3.12$; 95\% CI: $1.93-5.03$ ) and worse OS (HR $=2.33 ; 95 \% \mathrm{CI}: 1.61-3.38)$. Most results of the subgroup analysis in our study were consistent with the above survival results.

How does LVI impact on prognosis in an oncobiology sight? Previous research has revealed that tumor cells may have the ability to penetrate the walls of lymphovascular vessels in the early stages of cancer. ${ }^{31}$ Primitively, tumor invades lymphovascular vessels and then form cancer clusters. Both in animal models and in humans, cancer clusters can stimulate human 


\begin{tabular}{|c|c|c|c|c|c|}
\hline Study & $\begin{array}{c}\text { Events/N } \\
\text { LVI(+) }\end{array}$ & $\begin{array}{c}\text { Events/N } \\
\text { LVI(-) }\end{array}$ & & HR(95\%Cl) & P-interaction \\
\hline All patients & $45 / 96$ & $28 / 128$ & $\mapsto-1$ & $3.12(1.93,5.03)$ & \\
\hline \multicolumn{6}{|l|}{ Sex } \\
\hline Male & $35 / 72$ & $21 / 94$ & $\mapsto-1$ & $3.38(1.95,5.87)$ & 0.746 \\
\hline Female & $10 / 24$ & $7 / 34$ & $\longmapsto$ & $2.60(0.98,6.90)$ & \\
\hline \multicolumn{6}{|l|}{ Siewert type } \\
\hline$|+| \mid$ & $24 / 54$ & $19 / 91$ & 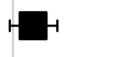 & $1.46(0.94,2.31)$ & 0.047 \\
\hline III & $21 / 42$ & $9 / 37$ & $\longmapsto$ & $3.20(1.45,7.06)$ & \\
\hline \multicolumn{6}{|l|}{ Differentiation } \\
\hline moderate-high & $11 / 36$ & $11 / 74$ & $\longmapsto$ & $3.08(1.30,7.28)$ & 0.942 \\
\hline low & $34 / 60$ & $17 / 54$ & $\mapsto$ & $2.56(1.43,4.60)$ & \\
\hline \multicolumn{6}{|l|}{ pT stage } \\
\hline $\mathrm{T} 1-2$ & $3 / 10$ & $3 / 33$ & $\longrightarrow$ & $5.57(0.93,33.44)$ & 0.522 \\
\hline T3-4 & $42 / 86$ & $25 / 95$ & $1-1$ & $2.63(1.60,4.33)$ & \\
\hline \multicolumn{6}{|l|}{ pN stage } \\
\hline pNo-1 & $13 / 29$ & $19 / 95$ & $\longmapsto$ & $2.859(1.39,5.89)$ & 0.801 \\
\hline pN2-3 & $32 / 67$ & $9 / 33$ & $\underbrace{\longmapsto}_{1.02 .04 .08}$ & $2.27(1.08,4.78)$ & \\
\hline
\end{tabular}

Figure 2 Forrest plot depicting IPW-adjusted HRs of DSS in the group of LVI(+) versus LVI(-) according to baseline covariates.

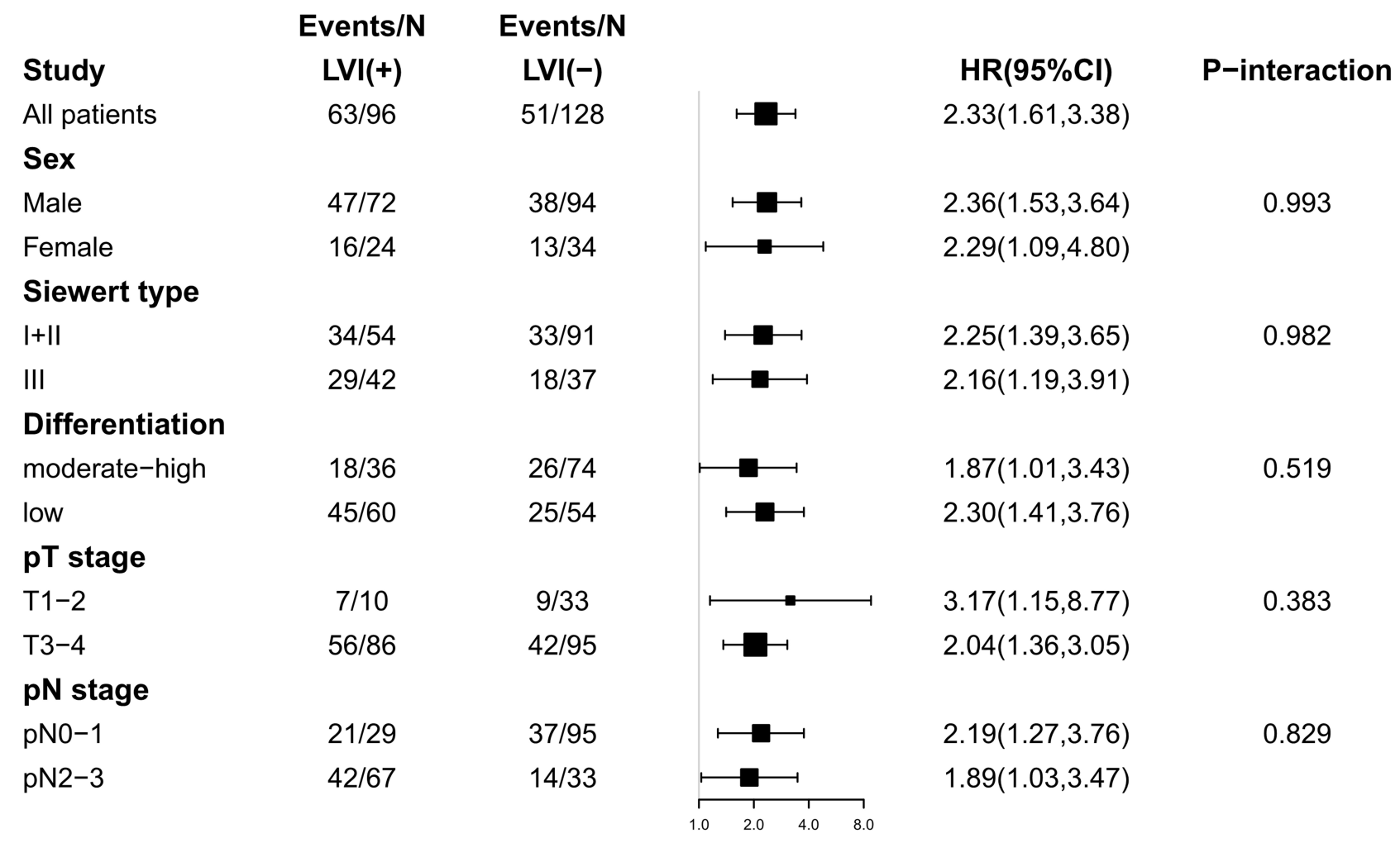

Figure 3 Forrest plot depicting IPW-adjusted HRs of OS in the group of LVI(+) versus LVI(-) according to baseline covariates. 
myoepithelial cells or murine embryonal fibroblasts to engage in encircling lymphovasculogenesis, which allows the clusters to become lymphovascular emboli. ${ }^{32}$ This process is regulated by the overactivity of the E-cadherin/ $\alpha$-catenin/ $\beta$-catenin axis, ${ }^{33,34}$ and the cells might express a cancer stem cell phenotype. ${ }^{18}$ Therefore, LVI biologically represents the progression of cancer and clinically indicates an adverse prognosis in AEG.

Finally, in subgroup analysis of survival, we found that DSS of Siewert type III tumors were more affected by LVI than of Siewert I/II (P-interaction $<0.05)$. It was previously reported that LVI was an independent prognostic factor for Siewert II/III, while it was not significant in Siewert type I. ${ }^{14}$ This may suggest that the closer they are to the stomach, the greater the effect of LVI on prognosis, which may be related to the etiological mechanism of AEG.

Our study had some limitations. This was a singleinstitute, retrospective study with few cases and a selection bias. Because of the uneven distribution of cases, subgroup analysis may have been affected by the small number of cases in some subgroups, although most of the other results were not affected by the number of study cases.

\section{Conclusion}

In general, the occurrence of LVI is related to worse DSS and OS. Siewert type III tumors seem to be more prone to developing LVI and more effective on long-term survival. Therefore, when formulating treatment plans, LVI should be considered, especially for patients with Siewert type III AEG, and more cautious plans should be adopted.

\section{Ethics Approval and Consent to Participate}

The study was approved by the research ethics committee of Guangdong Provincial People's Hospital and was performed in accordance with the standards of the Declaration of Helsinki. Patients admitted to the hospital have signed informed consent forms stating that clinical data during hospitalization can be used for anonymous retrospective studies, and it has been approved by the hospital ethics committee.

\section{Acknowledgments}

We wish to thank the Department of Pathology and Laboratory Medicine at our hospital and Empowerstats for their assistance in the pathological evaluation of LVI and data analysis.

\section{Author Contributions}

All authors made substantial contributions to conception and design, acquisition of data, or analysis and interpretation of data; took part in drafting the article or revising it critically for important intellectual content; agreed to submit to the current journal; gave final approval of the version to be published; and agree to be accountable for all aspects of the work. Contributed equally to this manuscript: Chengbin Zheng and Xingyu Feng.

\section{Funding}

This work was supported by the Supporting Scientific Research Fund of Outstanding Young Medical Talents of Guangdong Province, Guangdong Provincial People's Hospital (KJ012019439), 2019 Science and Technology Collaborative Innovation and Platform Environment Construction of Guangdong Province (International Science and Technology Cooperation Field) (2019A050510025).

\section{Disclosure}

All authors declare no conflicts of interest related to this article.

\section{References}

1. Kumamoto T, Kurahashi Y, Niwa H, et al. True esophagogastric junction adenocarcinoma: background of its definition and current surgical trends. Surg Today. 2020;50(8):809-814. doi:10.1007/ s00595-019-01843-4

2. Buas MF, Vaughan TL. Epidemiology and risk factors for gastroesophageal junction tumors: understanding the rising incidence of this disease. Semin Radiat Oncol. 2013;23(1):3-9. doi:10.1016/j. semradonc.2012.09.008

3. Liu K, Yang K, Zhang W, et al. Changes of esophagogastric junctional adenocarcinoma and gastroesophageal reflux disease among surgical patients during 1988-2012. Ann Surg. 2016;263(1):88-95. doi:10.1097/SLA.0000000000001148

4. Matsuno K, Ishihara R, Ohmori M, et al. Time trends in the incidence of esophageal adenocarcinoma, gastric adenocarcinoma, and superficial esophagogastric junction adenocarcinoma. $J$ Gastroenterol. 2019;54(9):784-791. doi:10.1007/s00535-019-01577-7

5. Lee JH, Chang KK, Yoon C, et al. Lauren histologic type is the most important factor associated with pattern of recurrence following resection of gastric adenocarcinoma. Ann Surg. 2018;267(1):105-113. doi:10.1097/SLA.0000000000002040

6. Hosokawa Y, Kinoshita T, Konishi M, et al. Clinicopathological features and prognostic factors of adenocarcinoma of the esophagogastric junction according to Siewert classification: experiences at a single institution in Japan. Ann Surg Oncol. 2012;19(2):677-683. doi:10.1245/s10434-011-1983-x

7. Urabe M, Ushiku T, Shinozaki-Ushiku A, et al. Adenocarcinoma of the esophagogastric junction and its background mucosal pathology: a comparative analysis according to Siewert classification in a Japanese cohort. Cancer Med. 2018;7(10):5145-5154. doi:10.1002/cam4.1763

8. Ishihara R, Oyama T, Abe S, et al. Risk of metastasis in adenocarcinoma of the esophagus: a multicenter retrospective study in a Japanese population. J Gastroenterol. 2017;52(7):800-808. 
9. Davies AR, Sandhu H, Pillai A, et al. Surgical resection strategy and the influence of radicality on outcomes in oesophageal cancer. $\mathrm{Br}$ J Surg. 2014;101(5):511-517. doi:10.1002/bjs.9456

10. Zhang H, Chen X, Wang S, Fan J, Lu L. Poorer prognosis associated with simultaneous lymphatic and vascular invasion in patients with squamous carcinoma of the thoracic oesophagus. Eur $j$ Cardio Thoracic Surg. 2017;52(2):378-384. doi:10.1093/ejcts/ezx081

11. Zhang CD, Ning FL, Zeng XT, Dai DQ. Lymphovascular invasion as a predictor for lymph node metastasis and a prognostic factor in gastric cancer patients under 70 years of age: a retrospective analysis. Int j Surg. 2018;53214.

12. Ji X, Yan Y, Bu Z-D, et al. The optimal extent of gastrectomy for middle-third gastric cancer: distal subtotal gastrectomy is superior to total gastrectomy in short-term effect without sacrificing long-term survival. BMC Cancer. 2017;17(1):345. doi:10.1186/s12885-0173343-0

13. Liu E, Zhong M, Xu F, et al. Impact of lymphatic vessel invasion on survival in curative resected gastric cancer. J Gastrointestinal Surg. 2011;15(9):1526-1531. doi:10.1007/s11605-011-1600-0

14. von Rahden BHA, Stein HJ, Feith M, Becker K, Siewert JR. Lymphatic vessel invasion as a prognostic factor in patients with primary resected adenocarcinomas of the esophagogastric junction. J clin oncol. 2005;23(4):874-879. doi:10.1200/JCO.2005.12.151

15. Hsu P-K, Chien L-I, Wang L-C, Chou T-Y. Lymphovascular invasion and extracapsular invasion are risk factors for distant recurrence after preoperative chemoradiotherapy and oesophagectomy in patients with oesophageal squamous cell carcinoma. Eur $j$ Cardio Thoracic Surg. 2017;51(6):1188-1194. doi:10.1093/ejcts/ezx029

16. Lee J-H, Kim J-H, Choi J-W, Kim Y-SKJ. The presence of a micropapillary component predicts aggressive behaviour in early and advanced gastric adenocarcinomas. Pathology. 2010;42 (6):560-563. doi:10.3109/00313025.2010.508790

17. Lu J, Dai Y, Xie J-W, et al. Combination of lymphovascular invasion and the AJCC TNM staging system improves prediction of prognosis in N0 stage gastric cancer: results from a high-volume institution. BMC Cancer. 2019;19(1):216. doi:10.1186/s12885-019-5416-8

18. Pei Q, Zhu H, Tan F, et al. Intravascular emboli is an independent risk factor for the prognosis of stage III colorectal cancer patients after radical surgery. Oncotarget. 2016;7(35):57268-57276. doi:10.18632/ oncotarget.11266

19. Hsu CP, Chuang CY, Hsu PK, et al. Lymphovascular invasion as the major prognostic factor in node-negative esophageal cancer after primary esophagectomy. J Gastrointestinal Surg. 2019;1:25.

20. Lagarde SM, Ten Kate FJW, Reitsma JB, Busch ORC, van Lanschot JJ. Prognostic factors in adenocarcinoma of the esophagus or gastroesophageal junction. J clin oncol. 2006;24(26):4347-4355. doi:10.1200/JCO.2005.04.9445

21. Zhang Y-F. Factors predicting survival in patients with proximal gastric carcinoma involving the esophagus. World j Gastroenterology. 2012;18(27):3602-3609. doi:10.3748/wjg.v18. i2 27.3602
22. Siewert J, Feith M, Werner M, Stein H. Wong Adenocarcinoma of the esophagogastric junction: results of surgical therapy based on anatomical/topographic classification in 1002 consecutive patients. Ann Surg. 2000;232(3):353-361. doi:10.1097/00000658-20000900000007

23. Rice TW, Ishwaran H, Hofstetter WL, et al. Recommendations for pathologic staging (pTNM) of cancer of the esophagus and esophagogastric junction for the 8th edition AJCC/UICC staging manuals. Dis Esophagus. 2016;29(8):897-905. doi:10.1111/dote.12533

24. Amin MB, et al. AJCC Cancer Staging Manual (8th Ed) [M]. New York: Springer; 2017:185-202.

25. Yamada M, Kushima R, Oda I, et al. Different histological status of gastritis in superficial adenocarcinoma of the esophagogastric junction. Jpn J Clin Oncol. 2014;44(1):65-71. doi:10.1093/jjco/ hyt 167

26. de Jonge PJF, van Blankenstein M, Grady WM, Kuipers Barrett's EJ. Barrett's oesophagus: epidemiology, cancer risk and implications for management. Gut. 2014;63(1):191-202. doi:10.1136/gutjnl-2013305490

27. Gertler R, Stein HJ, Schuster T, et al. Prevalence and topography of lymph node metastases in early esophageal and gastric cancer. Ann Surg. 2014;259(1):96-101. doi:10.1097/SLA.0000000000000239

28. Pyo JH, Lee H, Min YW, et al. Indication for endoscopic treatment based on the risk of lymph node metastasis in patients with Siewert type II/III early gastric cancer. Gastric Cancer. 2018;21(4):672-679. doi:10.1007/s10120-017-0789-3

29. Min B-H, Byeon S-J, Lee JH, et al. Lymphovascular invasion and lymph node metastasis rates in papillary adenocarcinoma of the stomach: implications for endoscopic resection. Gastric Cancer. 2018;21(4):680-688. doi:10.1007/s10120-017-0785-7

30. Wang Z, Chen P, Wang F, Lin L. Lymphovascular invasion as an independent prognostic indicator in radically resected thoracic esophageal squamous cell carcinoma. Thoracic Cancer. 2019;10 (2):150-155

31. Kukko HM, Koljonen VSK, Tukiainen EJ, Haglund CH, Bohling TO. Vascular invasion is an early event in pathogenesis of Merkel cell carcinoma. Modern Pathol. 2010;23(8):1151-1156. doi:10.1038/ modpathol.2010.100

32. Mahooti S, Porter K, Alpaugh ML, et al. Breast carcinomatous tumoral emboli can result from encircling lymphovasculogenesis rather than lymphovascular invasion. Oncotarget. 2010;1 (2):131-147. doi:10.18632/oncotarget.117

33. Tomlinson JS, Alpaugh ML, Barsky SH. An intact overexpressed E-cadherin/alpha, beta-catenin axis characterizes the lymphovascular emboli of inflammatory breast carcinoma. Cancer Res. 2001;61 (13):5231-5241.

34. Ye Y, Tian H, Lange AR, et al. The genesis and unique properties of the lymphovascular tumor embolus are because of calpain-regulated proteolysis of E-cadherin. Oncogene. 2013;32(13):1702-1713. doi:10.1038/onc.2012.180
Cancer Management and Research is an international, peer-reviewed open access journal focusing on cancer research and the optimal use of preventative and integrated treatment interventions to achieve improved outcomes, enhanced survival and quality of life for the cancer patient.
The manuscript management system is completely online and includes a very quick and fair peer-review system, which is all easy to use. Visit http://www.dovepress.com/testimonials.php to read real quotes from published authors. 